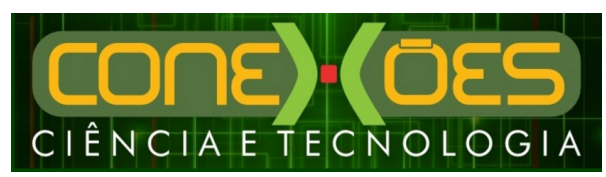

\title{
A GASTRONOMIA CEARENSE E SUA CONTRIBUIÇÃO AO TURISMO
}

\author{
LeOpoldo Gondim Neto $^{1}$, Gislleidy UchôA TAVARes ${ }^{1}$, Glaucia Posso Lima ${ }^{2}$ \\ ${ }^{1}$ Universidade Federal do Ceará - UFC, ${ }^{2}$ Universidade Estadual do Ceará - UECE \\ <chefleogondim@gmail.com>, <gislleidyuchoa@hotmail.com>. \\ <glaucia.posso@uece.br> \\ DOI: 10.21439/conexoes.v11i5.1320
}

\begin{abstract}
Resumo. O Ceará, conhecido como "Terra da Luz", de belas praias, um sertão rico em movimentos culturais e serras de clima com temperaturas amenas, sua culinária bastante diversificada, é uma potência na indústria do turismo nacional. A Gastronomia, quando utilizada como estímulo turístico, possibilita a construção de uma representação otimista e de reconhecimento dos costumes e da personalidade dos povos. Nesse sentido, no artigo objetivou-se, identificar a gastronomia e sua utilização nas atividades turísticas e destacar a culinária cearense como referencial gastronômico e representativo no Ceará. Tratase de uma pesquisa bibliográfica, aplicando o método de pesquisa descritiva, por meio de leituras com abordagem sobre o tema, selecionando aqueles de maior relevância para o estudo em questão. Assim, a particularidade da gastronomia regional, no momento em que é usufruída pelas práticas turísticas, coopera para uma maior disseminação dos usos e costumes regionais e, dessa forma, das culturas locais em que se aprimora o turismo. A gastronomia regional cearense é bastante apreciada pelos turistas e nativos, o que fortalece o turismo gastronômico. O Ceará destaca-se pela quantidade de atrativos turísticos naturais, históricos e culturais, havendo a necessidade de oferecer um alto padrão de qualidade nos serviços gastronômicos para o fortalecimento do turismo.
\end{abstract}

Palavras-chaves: Gastronomia Regional. Culinária Cearense. Turismo. Cultura.

\begin{abstract}
The Ceará, known as the "Terra da Luz", has beautiful beaches, a backwoods rich in cultural movements and mountain ranges with mild temperatures, its cuisine is very diverse, a power in the national tourism industry. Gastronomy, when used as a tourist stimulus, allows the construction of an optimistic representation and recognition of the customs and personality of the peoples. In this sense, the article aimed to identify gastronomy and its use in tourist activities and to highlight the cuisine cearense as a gastronomic and representative reference in Ceará. It is a bibliographical research, applying the descriptive research method, through readings with approach on the subject, selecting those of greater relevance for the study in question. Thus, the particularity of the regional gastronomy, when it is enjoyed by the tourist practices, cooperates for a greater dissemination of the regional uses and customs, and, therefore, of the local cultures in which tourism is improved. The regional gastronomy of Ceará is highly appreciated by tourists and natives, which strengthens gastronomic tourism. Ceará is distinguished by the number of natural, historical and cultural tourist attractions, and there is a need to offer a high standard of quality in gastronomic services to strengthen tourism.
\end{abstract}

Keywords: Regional Gastronomy. Culinary Cearense. Tourism. Culture.

\section{INTRODUÇÃO}

A alimentação tem relevância nos procedimentos nutritivos, no restabelecimento das forças vitais da estrutura física, no contentamento de preferências dos mantimentos e nos costumes de cada povo. Concebe como parte do dia a dia da sociedade e aparece em inúmeras oportunidades: na reunião familiar para fazer as refeições; no encontro com amigos; nas festas e ocasiões comemorativas e, em tantos outros momentos. Assim, a cultura de uma sociedade também pode ser representada por seus hábitos alimentares, pelas variáveis na determinação da 


\section{A GASTRONOMIA CEARENSE E SUA CONTRIBUIÇÃO AO TURISMO}

escolha de produtos culinários e pela relação existente entra a comida e identidade cultural da sociedade na qual está inserida (CARNEIRO, 2003).

A Gastronomia é elemento significativo na representação da identidade de uma comunidade e constituise parte integrante da cultura, estando presente na memória da sociedade. As especificidades da gastronomia regional são compreendidas na seleção dos constituintes temperos; no procedimento do preparo, na função dos mantimentos e na definição do momento, da ocasião e de que maneira deve ser aprontado cada refeição, e se eles são ingeridos em alimentações cotidianas ou em momentos específicos (ALMEIDA, 2003)

No Brasil, a culinária é diversificada, apresentando características peculiares dependendo da região, dos ingredientes disponíveis e das formas de preparo. Dessa forma, o potencial de uso da gastronomia apresentase como uma tendência que pode ser utilizada pelo turismo (CASCUDO, 2004). A adequada inserção deste fabuloso bem cultural aliado a um padrão de qualidade nos serviços gastronômicos pode contribuir, de forma decisiva, para o incremento do setor e o fortalecimento da economia e do turismo cearense (FRANCO, 2001).

Considerando tais características, o artigo tem como objetivo identificar a cozinha cearense e sua utilização nas atividades turísticas, destacando aspectos da gastronomia e do turismo no Ceará. Trata-se de uma pesquisa bibliográfica, por meio de leituras em artigos livros, monografias, dissertações, teses, textos, jornais, periódicos, revistas, guias e sites da internet, com abordagem sobre o tema "A Gastronomia Cearense e sua Contribuição ao Turismo", selecionando aqueles de maior relevância para o estudo em questão. Empregando o método de pesquisa descritiva que têm como objetivo primordial a descrição das características de determinada população ou fenômeno ou, então, o estabelecimento de relações entre variáveis (GIL, 2002).

\section{ASPECTOS CULTURAIS E SOCIAIS NA ALI- MENTAÇÃO}

Entende-se por pratos regionais aqueles que são ingeridos em uma localidade específica e que simboliza a personalidade e a herança imaterial dos povos em lugar demarcado. É capaz de considerar-se como culinária típica aquela construída pelo povoamento, para obtenção pessoal, aproveitando de artefatos de uso cotidiano, comumente relevante e de aquisição acessível, possuindo essencial a sua degustação, produtos que representam a existência real da comunidade que a detém. Desta forma, pode-se afirmar que as comidas preparadas e/ou absorvida por uma população consegue ser conhecida como porção constituinte da culinária típica, no momento em que caracteriza aquela população (ROCHA. 2003).

Os pratos regionais e os pratos típicos podem ser um atrativo a mais para o turista, que busca em suas viagens, junto com o alimento e a satisfação de suas necessidades básicas de nutrição, conhecer um pouco mais sobre a cultura e a história da localidade visitada. Devido ao aspecto cultural, o que se come, passa a representar o modo de ser e viver de grupos sociais que se identificam pelo estilo de alimentação adotada. A alimentação passa a ser não apenas a reposição de nutrientes necessários à vida humana e sim, a representar grupos sociais com diferentes hábitos alimentares (DIAS) 2003)

Tais hábitos cotidianos dos povos tornam-se objetos de estudo, pois:

a alimentação é (...) um fato da cultura material, da infra-estrutura da sociedade; um fato da cultura e do comércio, da história econômica e social, ou seja, parte da estrutura produtiva da sociedade. Mas também é um fato ideológico das representações - religiosas, artísticas e morais - ou seja, um objeto histórico complexo, para o qual a abordagem cientifica deve ser multifacetada (CARNEIRO, 2003, p.166)

A função social que a alimentação tem em uma sociedade, retrata traços de sua identidade cultural e o papel que ocupa nas relações humanas, aproximando as pessoas das suas origens. "Desde os tempos imemoriais e alimentação ocupa um lugar de suma importância nas relações entre os povos" (ANSARAH, 2001, BARRETO, 2002). Dentre outros princípios, os mantimentos transformam-se em parte da personalidade dos povos, sendo capaz de constituir uma maneira de identificar as comunidades e de familiarizar-se com outros diferentes hábitos, por meio da degustação de novas refeições e paladares (SANTOS, 1995). .

A gastronomia torna-se um exemplo de referência social, os hábitos alimentares constituem um enraizamento, uma identidade cultural, que pode ser analisada como tantos outros fatores na formação social e cultural. Os modos de preparo, determinados ingredientes, temperos e pratos, constituem o patrimônio cultural dos povos (CALDAS, 1986). 


\section{A CULTURA GASTRONÔMICA E SUA UTILI- ZAÇÃO NAS ATIVIDADES TURÍSTICAS}

O brasileiro, surge da confluência cultural entre os povos colonizadores, índios e negros, permitindo uma troca de hábitos e de costumes que proporcionam a constituição social e cultural do Brasil. Desta forma, a composição da sociedade brasileira assume características próprias, tendo por influência aspectos da cultura português, da cultura indígena e da cultura africana.

A culinária brasileira é formada por este conjunto de culturas e etnias que gerou o país e pela influencias de inúmeros povos. Pode-se considerar, segundo autores como Fernandes (2001), Freyre (2003) e Cascudo (2004), que a culinária brasileira teve início nas tradições indígenas. O ajuntamento de práticas e hábitos gastronômicos beneficiou o gosto brasileiro criando as diversas culturas de práticas culinárias locais que permanecem na atualidade. A maneira de vida regional tem atuado nos hábitos culinários resultando no aparecimento das diferenças regionais, trazendo traços culinários típicos de cada localidade. Cada região tem características, marcas do passado e geografia, não se limitando apenas a isso, que determinam sua comida típica.

O uso da alimentação, para agregar valos às atividades turísticas, deve partir de um estudo profundo das raízes gastronômicas e de suas influencias na sociedade e do modo com que os costumes foram se fixando com o desenvolvimento local. A definição da cozinha brasileira é algo extremamente complexo, por possuir influências múltiplas e diferenças entre si. Mesmo delimitando uma região de menor dimensão que o Brasil como um todo, ainda é difícil uma única identidade gastronômica (CASCUDO, 2004).

Assim, o turismo pode ser entendido como um fenômeno social moderno que estabelece interações sociais nos mais diversos setores da sociedade, proporcionando trocas entre as culturas, relações econômicas e sociais. O fenômeno turismo está intrinsecamente relacionado a todas as características da sociedade e dos sistemas que ela apresenta, classificando-se em

o turismo motivado pela busca de atrativos naturais e o turismo motivado pela busca de atrativos culturais. Assim, entende-se por "turismo cultural" todo turismo em que o principal atrativo não seja a natureza, mas alguém aspecto da cultura brasileira. Esse pode ser a história, o cotidiano, o artesanato, ou qualquer outro dos inúmeros aspectos que o conceito de cultura abrange (BARRETO
2002, p.19)

O turismo cultural, por exemplo, retrata como motivação fundamental os saberes de uma comunidade distinta seja através de suas obras concretas ou de demonstrações abstratas, na qual o viajante vivencie e compreenda o tipo e, inclusive, as parecenças, quando comparado à sua realidade. A gastronomia faz parte deste diferencial que pode ser representado pelo turismo (RUSCHMANN, 1997).

O turismo deve ser avaliado também como um recurso de preservação cultural e uma constante busca entre o equilíbrio, para não cair no extremo da mercantilização da cultura, utilizado de forma a divulgar as riquezas naturais e históricas, bem como a cultura dos povos e sua diversidade (DIAS, 2003).

O turismo gastronômico é uma das atividades ligadas ao turismo que é apoiada pelo Instituto Brasileiro de Turismo (EMBRATUR, 2004). Está diretamente ligada ao prazer e à sensação de sociedade, adquirida através da comida, durante a viagem. Algumas regiões brasileiras aproveitam sua cultura, história e tradições, e a divulgam através da gastronomia, lançando um produto turístico vinculado à gastronomia típica (EMBRATUR. 2004). Por isso o turismo gastronômico torna-se uma categoria do turismo cultural em que o viajante é capaz de compreender a cultura e o modo de vida dos povos em que se visita, por meio, mas não apenas, das demonstrações culinárias (SCHLUTER, 2003).

A relação entre turismo e gastronomia evidenciase, segundo Flandrin e Montanari (1998), a contar de 1920, momento em que acontece uma conturbação divergente à cozinha urbana das localidades extensas. A partir deste momento, considerada como culinária irreal e sem gosto, esforça-se retomar e reconhecer os pratos regionais, com a colaboração do turismo automotivo. Desde essa época, deu-se uma procura pelas culinárias regionais, que se converteram em incentivo de viagem.

Nos estados do Nordeste brasileiro, o turismo tem sido nos últimos anos uma das maiores alternativas para o crescimento econômico, o sol que antes era uma adversidade na região, passou a ser um aliado, sendo um atrativo com a sua incidência o ano inteiro (TRIGO, 2001). O Ceará, apresenta ainda três ecossistemas, compreendidos pelo litoral, serra e sertão que garantem a diversidade ambiental e o diferencial para os produtos turísticos ofertados (SARAIVA, 2002).

Para auxiliar as políticas relativas ao desenvolvimento do turismo sustentável com base no planejamento estratégico de longo prazo, foi criado o Programa de Desenvolvimento do Turismo do Nordeste (PRODETUR), que tem ações voltadas para a infraestrutura bá- 


\section{A GASTRONOMIA CEARENSE E SUA CONTRIBUIÇÃO AO TURISMO}

sica dos municípios fomentando a oferta turística, contribuindo para o desenvolvimento econômico dos estados. Dentro do objetivo do PRODETUR está também a preservação dos aspectos culturais, produtivos e administrativos dos municípios, procurando equilibrar as obras com as condições ambientais, garantindo assim a melhoria da qualidade de vida da população (SETUR 2005).

Desde o final da década de 1980, o governo do Ceará investe maciçamente na modernização do Estado e, por conseguinte na cidade de Fortaleza, bem como na atração de investimentos em negócios turísticos. Assim, o turismo passou a ser um dos principais vetores da reorganização espacial do litoral cearense, o que pode ser evidenciado pela dinâmica da zona litorânea de Fortaleza (FRANCO, 2001). O litoral de Fortaleza é visto como território privilegiado para a atração de turistas, para a venda de produtos, para a implantação de equipamentos turísticos, e espaço feito espetacular, sobretudo, disposto e reorganizado como cartão de visitas e atrativos para os investimentos turísticos (PONTE, 2004).

É um dos estados brasileiros que oferece uma das maiores diversidades de paisagens, as praias, os sertões, serras e cidades com história de lutas e desafios. A hospitalidade do povo cearense é uma marca registrada que transforma o estado, juntamente com uma culinária regional rica e original em um destino turístico irresistível, e nos últimos anos passou a ser visto por emissores mundiais, como um destino turístico privilegiado (SETUR, 1998).

\section{RESULTADOS E DISCUSSÃO}

A cozinha tradicional cearense, assim como a cozinha tradicional brasileira é uma mistura de sabores da cozinha portuguesa, com a cozinha indígena em trações bem fortes e a cozinha da África (CASCUDO. 2004). Na primeira fase da história cearense, o pouco desenvolvimento regional se manteve na orla marítima, baseando-se no plantio de cana-de-açúcar (SOUSA 2000). A partir da última década do século XVIII, acelerou-se a interiorização, partindo para uma economia essencialmente pecuarista. Os currais foram se transformando em fazendas e a carne de sol, o jabá, ou seja, a carne salgada, passou a ser o produto mais transportado para os grandes centros de consumo. A carne charqueada se mantém como principal produto até a grande seca do final do século XVIII, quando a grande maioria dos rebanhos morre (FERNANDES, 2001).

A culinária cearense baseia-se na pesa, na pecuária e algumas culturas agrícolas, são mescladas da estética e da pratica apolínea e dionisíaca, que é produzir o ali- mento e depois consumi-lo festivamente. Onde a cultura da pecuária, com a criação do gado e do caprino, traz a alimentação derivada, o leite, o queijo de coalho, a coalhada, a manteiga da terra, a nata, a carne assada e cozida, a panelada, e tudo isso faz parte da cozinha e mesa cearense (FERNANDES, 2001).

O sarrabulho, panelada, buchada, galinha cabidela (ver Figura 1) e carneirada são característicos do sertão, são pratos que se destacam como referencial gastronômico regional pois apresentam um histórico, um vínculo com a comunidade, retrata a cultura e uma realidade local (FRANCO, 2001).

Figura 1: Galinha Capidela

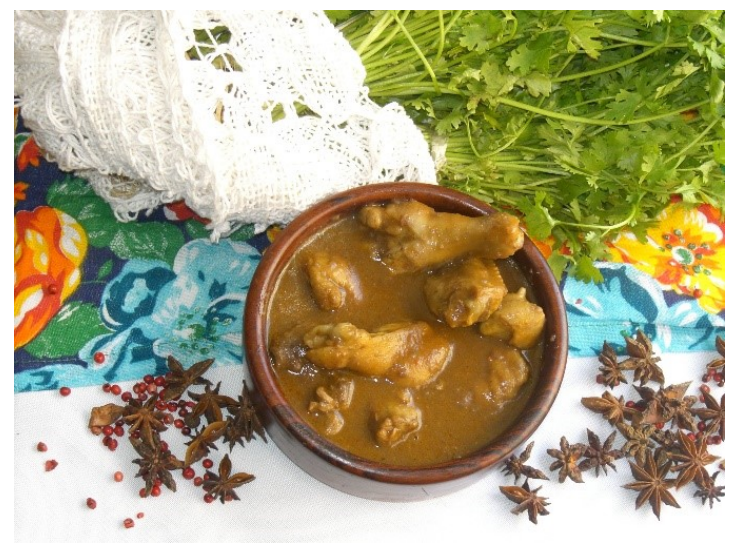

Fonte: Gondim Neto

As festas juninas, com tradições religiosas, trouxeram comidas e bebidas típicas que são intensamente consumidas durante o período. Os aluás de milho, pão e abacaxi, os bolos de batata, milho, macaxeira, carimã, pé-de-moleque, grude, canjica, pamonha, milho cozido e assado, paçoca, churrasquinhos em espeto e baião-dedois (FRANCO, 2001). A rapadura aqui, merece destaque por sua história, aja visto que esta é fruto das moendas puxadas por bois ou muitas vezes por escravos.

As casas de farinha espalhadas por todo o $\mathrm{Ce}$ ará, trabalham a mandioca, sendo uma contribuição valorosa do indígena com técnicas até hoje utilizadas (FRANCO, 2001). Também das casas de farinha vem à goma, caldo da primeira etapa do trabalho com a mandioca, e que é colocado para secar em vasilha separada, e que vai ser o ingrediente principal da famosa tapioca (ver Figura 2), um dos pratos típicos mais saborosos do Ceará e do Nordeste. Da mandioca também vem o carimã, que substituiu a farinha de trigo dos portugueses na preparação de mingaus e bolos (CASCUDO, 2004).

$\mathrm{O}$ índio também foi o grande influenciador da forma como hoje consumimos o pirão, outro prato feito com a 


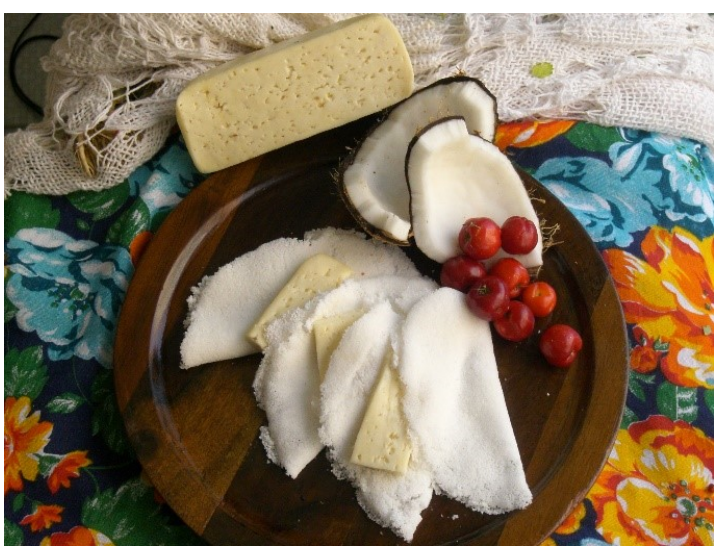

Fonte: Gondim Neto

farinha de mandioca e caldos de peixe, da carne, da panelada e outros, podendo ser escaldado, cozido ou mexido (FERNANDES, 2001). A contribuição indígena vem além dos peixes de água doce e salgada, tão apreciados pelos portugueses, as frutas silvestres como o murici, pitanga, jenipapo, jatobá, cajá, macaúba, caju e sua castanha tão valorizadas (CASCUDO, 2004).

O Ceará tem uma costa privilegiada com praias muito belas e ao longo destas existem diversos povoados e cidades, que possuem uma culinária específica, baseada em derivados do mangue, como camarão, ostra, caranguejo, aratu, sururu e peixes, entre estes, a cavala, a serra, a garoupa, a cioba, o pargo, o ariacó, a biquara e o cangulo. Um dos símbolos da culinária cearense, a lagosta é um produto do mar muito requisitado pelos turistas e a comunidade mais abastada, o Ceará é grande exportador e Fortaleza mantém o posto de preparar a melhor lagosta do Brasil (FRANCO, 2001).

A cozinha predominante em Fortaleza tem características nordestinas ressaltando-se pratos típicos como o baião-de-dois (ver Figura 3) com churrasco de carneiro ou carne-de-sol (ver Figura 4). Frutos do mar tais como moqueca de arraia, peixadas de cavala e pargo (ver Figura 5), são outros ingredientes de pratos típicos da cozinha fortalezense. O camarão também é um fruto do mar bastante degustada em pratos como o "arroz de camarão" ou "bobó de camarão" ou mesmo passado no "alho e óleo".

\section{CONSIDERAÇÕES FINAIS}

A gastronomia é vista como algo relevante para definir a identidade de uma comunidade, pois ela está presente em sua rotina e em sua parte integrante, assim a

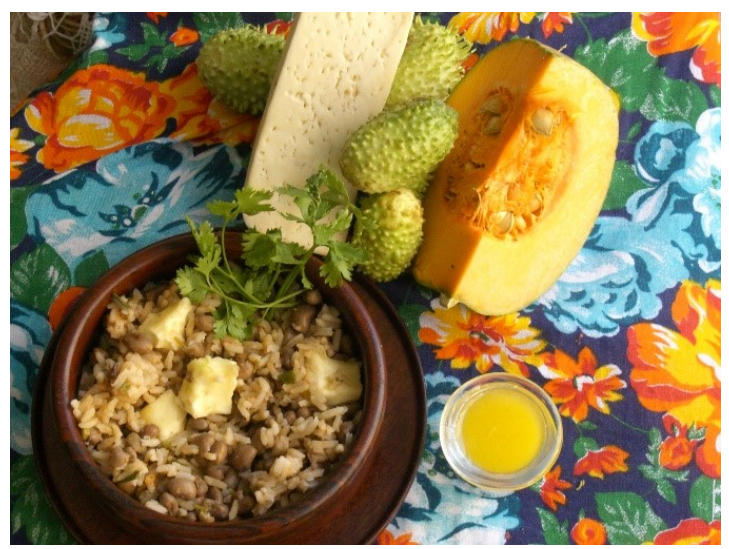

Fonte: Gondim Neto

Figura 4: Carne de Sol

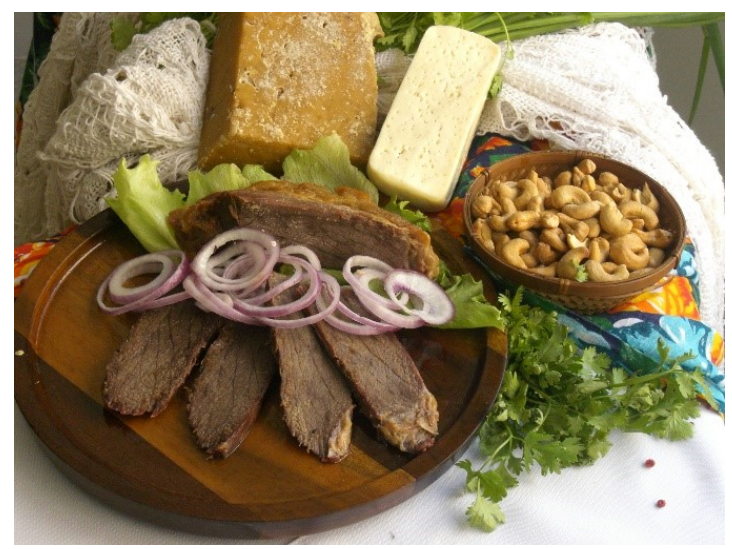

Fonte: Gondim Neto

cultura e a alimentação se tornam interligadas, pois a alimentação de uma comunidade está relacionada principalmente à sua cultura, representada pelos membros que compõem determinada sociedade. Por meio de seus costumes alimentares uma sociedade é capaz de mostrar seus gostos, suas influências e até mesmo suas características.

Assim, o estado pode apresentar desde o mais rustico ambiente do sertão, com casas de taipa e culinária peculiar a base de carne-de-sol e farinha até os mais elaborados projetos arquitetônicos com a culinária internacional. A Gastronomia Cearense tem um cardápio para todos os gostos, como opções que vão de frutos do mar até comidas típicas que revelam verdadeiras delicias, como a tapioca, panelada, buchada, carne-de-sol, e o baião-de-dois. Os peixes, frutos do mar e crustáceos, sem dúvida, são os pratos preferidos pelos turistas.

A Gastronomia, portanto, está inserida na atividade 
Figura 5: Peixada

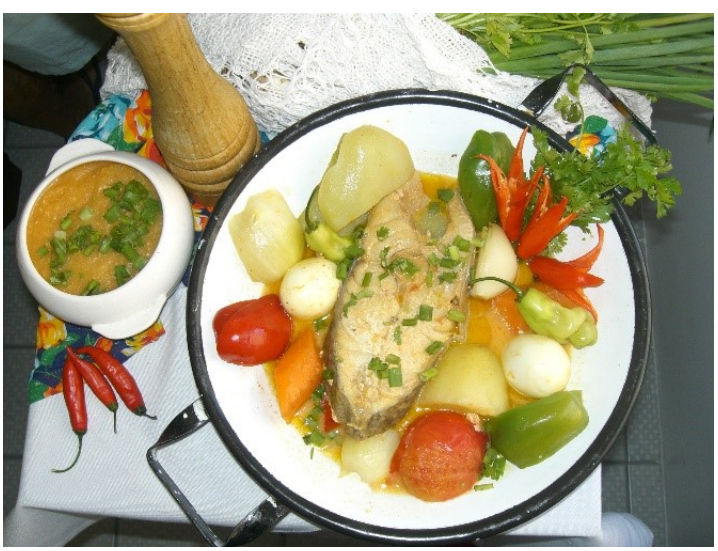

Fonte: Gondim Neto

turística, pois o viajante necessita da alimentação, primeiramente por um aspecto fisiológico, mas também porque a alimentação é também fonte de prazer e experiência, que ocorre através da degustação de novos pratos e formas de preparo nos locais visitados. A gastronomia regional cearense, quando utilizada pelas atividades turísticas, fortalece a imagem regional, valoriza a cultura e o patrimônio histórico e cultural, agregandose a natureza e a outros atrativos. A busca das raízes culinárias e a forma de entender a cultura de um lugar por meio de sua gastronomia estão adquirindo importância cada vez maior, assim, a consolidação do turismo regional torna-se uma fonte de desenvolvimento econômico e social.

\section{REFERÊNCIAS}

ALMEIDA, S. A. P. de. Desenvolvimento regional do turismo em áreas com potencial cultural e natural. Dissertação (Mestrado) — Turismo e Hotelaria Universidade Federal de Santa Catarina, Balneário Camboriú, 2003.

ANSARAH, M. R. Turismo: como aprender, como ensinar. São Paulo: SENAC, 2001.

BARRETO, M. Turismo e legado cultural. 2. ed. Campinas: Papirus, 2002.

CALDAS, W. Cultura. 4. ed. São Paulo: Global, 1986.

CARNEIRO, H. Comida e sociedade: uma história da alimentação. Rio de Janeiro: , 2003.

CASCUDO, L. C. História da alimentação no Brasil. São Paulo: Global, 2004.
DIAS, R. Sociologia do Turismo. São Paulo: Atlas, 2003.

EMBRATUR. Ministério do Turismo: Brasílias. 2004. Disponível em: <http://www.embratur.gov.br/>

FERNANDES, C. Viagem gastronômica através do Brasil. São Paulo: SENAC, 2001.

FLANDRIN, J.; MONTANARI, M. História da alimentação. São Paulo: Estaçãp Liberdade, 1998.

FRANCO, A. De caçador a Goumet uma história da gastronomia. 2. ed. São Paulo: SENAC, 2001.

FREYRE, G. Casa grande e senzala: formação da família brasileira sobre o regime da economia patriarcal. São Paulo: Global, 2003.

GIL, A. C. Como classificar as pesquisas. Como elaborar projetos de pesquisa, Atlas São Paulo, v. 4, p. 41-57, 2002.

PONTE, S. R. A belle époque em fortaleza: remodelação e controle. In: SOUZA, S. d. (Ed.). Uma nova história do Ceará. 3. ed. Fortaleza: Edições Demócrito Rocha, 2004.

ROCHA, D. Sabores e sabores do Ceará. Fortaleza: Edições Demócrito Rocha: , 2003.

RUSCHMANN, D. Turismo e planejamento sustentável: a proteção do meio ambiente. Campinas: Papirus, 1997.

SANTOS, C. R. A. História da Alimentação no Paraná. Curitiba: Farol do Saber, 1995.

SARAIVA, M. L. S. A. Faces dos novos usos do território litorâneo: lazer e turismo em Praia das Fontes e Prainha do Canto Verde, Beberibe, Fortaleza. Dissertação (Mestrado) — Programa de Pós-Graduação em Geografia da Universidade Estadual do Ceará, 2002.

SCHLUTER, R. Gastronomia e turismo. São Paulo: Aleph, 2003.

SETUR, S. Plano da SETUR - Turismo: Uma política estratégica para o desenvolvimento sustentável no Ceará. 1995 - 2020. Fortaleza: SETUR, 1998.

Estudos Turísticos da SETUR número 22 - Considerações sobre os Mercados Emissores Potenciais de Turismo para o Ceará. Fortaleza: SETUR, 2005. 
SOUSA, S. Uma nova história do Ceará. Fortaleza:

Edições Demócrito Rocha: , 2000.

TRIGO, L. G. G. Turismo básico. 7. ed. São Paulo:

SENAC, 2001. 